\title{
An Ancient Wolf, Canus lupus, Den and Associated Human Activity in the Southwestern Yukon Territory
}

\author{
Richard FARNelL ${ }^{1}$, P. GREgory HARE ${ }^{2}$, and DANiEl R. DRUMmOND ${ }^{1}$
}

${ }^{1}$ Department of Environment, Government of Yukon, Box 2703, Whitehorse, Yukon, Y1A 2C6 Canada

${ }^{2}$ Department of Tourism and Culture, Government of Yukon, Box 2703, Whitehorse, Yukon, Y1A 2C6 Canada

Farnell, Richard, P. Gregory Hare, and Daniel R. Drummond. 2005. An ancient wolf den and associated human activity in the southwestern Yukon Territory. Canadian Field-Naturalist 119(1): 135-136.

The recovery of an ancient hunting artifact in an active Wolf den indicates that Wolf denning sites may be reused for many centuries. It also suggests that traditional practices of predator management by humans may have great antiquity.

Key Words: Wolf, Canis lupus, den, archaeology, bow and arrow, Yukon.

Yukon Wolves, Canis Lupus, typically dig dens in May to rear pups (Rausch 1967). They may occupy the same den for several consecutive years or intermittently over long periods; however, the long-term persistence of Wolf dens in the Yukon has not been explored. The recent recovery of an antler arrow point within a Wolf den provides evidence that Wolves may return to the same denning sites over many centuries.

In May 1995, during a routine monitoring visit to a Wolf den in a remote area of southwestern Yukon, DRD [Daniel R. Drummond] entered an entrance tunnel leading to the main chamber (Figure 1). Here, he found and extracted a barbed antler point that was embedded in the tunnel side-wall near the tunnel entrance. The projectile point is typical of a style of point used by Southern Tutchone hunters throughout the past 1200 years (Hare et al. 2004) (Figure 2). The artifact was

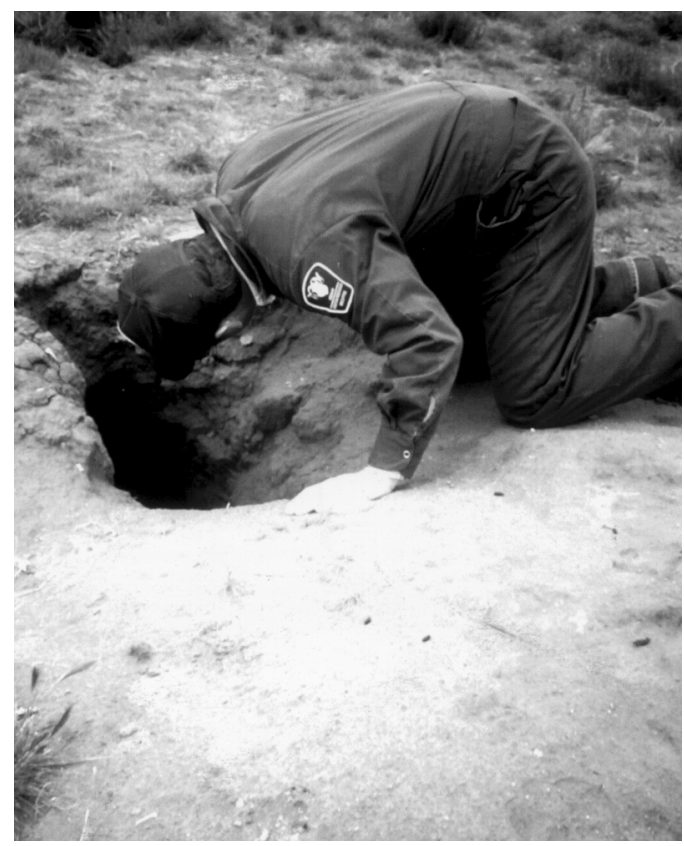

FIGURE 1. Photo of D. Drummond examining entrance of Kloo Lake den tunnel.

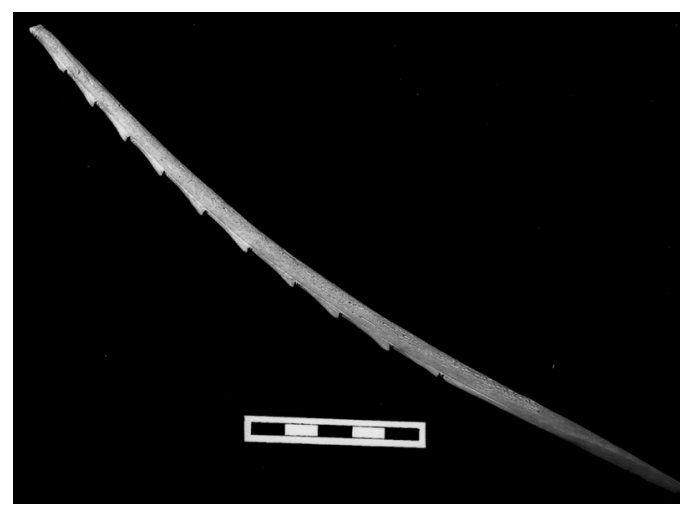

FIGURE 2. Photo of barbed antler arrow point (scale bar in centimeters).

submitted to Beta Analytic Laboratories for AMS radiocarbon dating and returned a date of $850 \pm 50$ B.P. (Beta-162350).

This date provides evidence that the den was in use by at least 1040 to $1270 \mathrm{AD}$ (calibrated, 2 Sigma variation). While there was significant amount of bioturbation at the site, the excellent preservation of such a fragile, organic artifact indicates that the projectile point has remained in buried, dry conditions for most of that entire period.

The southwest Yukon den $\left(61^{\circ} \mathrm{N} 5^{\prime}, 137^{\circ} \mathrm{W} 54^{\prime}\right)$ is known as the Kloo Lake den. It was monitored annually for reproductive activity from 1992 to 1998 for a Wolf fertility control experiment (Spence 1998). The den characteristics are typical of those found in Yukon and Alaska (A. Baer, Yukon Department of Environment, unpublished data; Ballard and Dau 1983). The den site is well suited for Wolves. It has a southern exposure and is situated on an old elevated river terrace composed of very stable frost-free lacustrine soils. It is located in a mixed open stand of spruce (Picea spp.), Trembling Aspen (Populus tremuloides), and willow (Salix spp.). It overlooks a large valley composed mostly of wetland traversed by the Jarvis River which flows into Kloo Lake $13 \mathrm{~km}$ downstream. There is substantial prey available in the area as it is situated in close proximity to calving and summer habitats of Woodland 
Caribou (Rangifer tarandus caribou) and Moose (Alces alces) (Hayes et al. 2003). Caribou in particular are known to have occurred in the area in large numbers for at least 8000 years (Farnell et al. 2004).

There are several possible explanations to account for a barbed antler projectile point at this Wolf den. An ancient hunter may have lost the projectile point while "Wolf denning" or attempting to kill a wolf to use the hide for clothing many centuries ago. Alternatively a Wolf or other predator or scavenger could have transported prey remains with the point embedded from a previously wounded animal. Likewise, a hunter could have wounded a Wolf that subsequently returned to the den site. There is also the possibility that a hunter may have inadvertently dropped the projectile point at this location.

It is possible that the Wolf den was recently constructed on top of an archeological site that contained an antler point but this situation is highly unlikely. Two site inspections (2002 and 2003) of the Wolf den demonstrated that despite large surface exposures and sediment upheaval there was no other archeological evidence at the site (e.g., lithics, burned bone, charcoal, fire cracked rock).

Knowledge of historical locations of Wolf dens and the cultural and the traditional practice of "Wolf denning" (e.g., culling or capturing Wolf pups at dens during spring) is documented in both Yukon First Nation oral history and ethnographic documentation (Johnson 1994*; Allen 1993*; LeGros 1981*; Art Johns, Carcross/Tagish First Nation elder personal communication to R. Farnell, Tom Smith, Kaska Dena elder, commentary in Northern Native Broadcastings, "The Come Back Trail" 1988; Percy Henry, Tr'on dek Hwech'in, elder testimony to Alaska Board of Game, Anchorage, Alaska 1998). If the recovery of an 850year-old arrow point within a den is related to the practice of "Wolf denning", it indicates that it is a traditional practice of long standing. It is also possible that it resulted from an effort to obtain Wolf pelts for use in clothing. However this seems unlikely as Wolf pelts are in extremely poor condition during spring and summer.

In view of the persistence of Wolf den reuse, it is possible that native hunters could have used predictable denning behavior to reduce interspecific competition for common prey. There is a large body of evidence that Wolves limit Caribou and Moose numbers (Hayes et al. 2003). At the same time, Moose and Caribou were critical to the survival of subarctic Southern Tutchone. Reducing Wolf numbers at dens would have improved the likelihood of success in hunting.

Mech and Packard (1990) first reported evidence for possible use of a Wolf den spanning a period of 700 years or more on Ellesmere Island, Northwest Territories based on fossil prey remains. On Ellesmere, Wolves cannot dig dens because of permafrost. The Ellesmere denning site was a cave and there are few in the area making it a uniquely suitable location. In Yukon, den longevity must rely on substrate stability and suitable regional prey availability-conditions that must have persisted at the Kloo Lake den for many centuries. At our latitude Wolves have many options for places to den; yet a surprising proportion of dens are reused. It may be that wolves are attracted to places previously used by other Wolves and this is an important factor in the continued use of some dens.

\section{Acknowledgments}

The Yukon Department of Environment and Department of Tourism and Culture supported this study. Suggestions provided by Robert O. Stephenson, Alaska Department of Fish and Game, Fairbanks, and Layne G. Adams, U. S. Geological Survey, Alaska Science Center, Anchorage are greatly appreciated.

\section{Documents Cited (marked* in text)}

Allen, J. 1993. Traditional knowledge report: Aishihik caribou recovery area. Champaign and Aishihik First Nation and Yukon Department of Environment. Whitehorse, Yukon.

Johnson, M. 1994. Aishihik and Kluane caribou recovery: A summary of Kluane First Nation traditional knowledge interviews and recommendations. Kluane First Nation and Yukon Department of Environment, Whitehorse, Yukon.

LeGros, D. 1981 Structure Socio-Culturelle et Rapports De Domination Chez Les Indiens Tutchone Septentrionaux du Yukon au Dix-Neuviene Siecle. Unpublished Ph.D. thesis, University of British Columbia.

\section{Literature Cited}

Ballard, W. B., and J. R. Dau. 1983. Characteristics of Gray Wolf, Canis lupus, den and rendezvous sites in Southcentral Alaska. Canadian Field-Naturalist 97: 299-302.

Farnell, R., P. G. Hare, S. Greer, E. Blake, V. Bowyer, and C. Schweger. 2004. Multidisciplinary investigations of alpine ice patches in Southwest Yukon, Canada: Paleoenvironmental and paleobiological investigations. Arctic 57: 247-259.

Hare, P. G., S. Greer, R. Gotthardt, R Farnell, V. Bowyer, and C. Schweger. 2004. Multidisciplinary investigations of alpine ice patches in Southwest Yukon, Canada: Ethnographic and archaeological investigations. Arctic 57: 260-272.

Hayes, R. D., R. Farnell, R. M. P. Ward, J. Carey, M. Dehn, G. W. Kuzyk, A. M. Baer, C. L. Gardner, and M. O'Donoghue. 2003. Experimental reduction of wolves in Yukon: ungulate responses and management implications. Widlife Monographs 152.

Mech, L. D., and J. M. Packard. 1990. Possible use of wolf, Canis lupus, den over several centuries. Canadian FieldNaturalist 104: 484-485.

Rausch, R. A. 1967. Some aspects of population ecology of wolves, Alaska. American Zoologist 7: 253-265.

Spence, C. E. 1998. Fertility control and the ecological consequences of managing northern wolf populations. M.S. thesis. Department of Botany. University of Toronto, Toronto, Ontario.

Received 26 January 2004

Accepted 21 February 2005 